\title{
Effect of solution-blended poly(styrene-co-acrylonitrile) copolymer on crystallization of poly(vinylidene fluoride)
}

\author{
Q. Xia ${ }^{1}$, X. J. Zhao, S. J. Chen ${ }^{1}$, W. Z. Ma1 , J. Zhang1* X. L. Wang ${ }^{2}$ \\ ${ }^{1}$ College of Materials Science and Engineering, Nanjing University of Technology, Nanjing, 210009, China \\ 2Department of Chemical Engineering, Tsinghua University, Beijing 100084, China
}

Received 16 December 2009; accepted in revised form 5 March 2010

\begin{abstract}
Effect of solution-blended poly(styrene-co-acrylonitrile) (SAN) copolymer on crystallization of poly(vinylidene fluoride) (PVDF) was investigated by Fourier transform infrared spectroscopy (FTIR), differential scanning calorimetry (DSC) and wide angle X-ray diffraction (WAXD). Acrylonitrile segment in SAN copolymer was partially miscible with PVDF. Styrene segment in SAN reduced the copolymer's polarity and its miscibility with PVDF. FTIR and WAXD tests both showed as-prepared PVDF was mainly $\beta$-phase. We employed an index $A_{\beta}$ divided by $X_{c}$, suggesting that blended SAN could decrease the content of $\beta$-phase of PVDF. By DSC, the smaller content of PVDF made the system more miscible so that the $T_{g, \mathrm{SAN}}$ of pure SAN decreased from 86.6 to $81.6^{\circ} \mathrm{C}$ of sample PVDF/SAN $=20 / 80$; further increase PVDF to $50 / 50$, the $T_{g, \text { SAN }}$ had a relative increase to be $84.2^{\circ} \mathrm{C}$. However, for SAN by melt molding, $T_{g, \text { SAN }}$ increased with the increase of PVDF content, which might be due to the incorporation of SAN into inter-spacing of PVDF lamellae, because PVDF molecular chains had not enough mobility to retreat from the SAN's embrace and crystallize despite of the exit of SAN.
\end{abstract}

Keywords: polymer blends and alloys, poly(vinylidene fluoride), poly(styrene-co-acrylonitrile), solution crystallization, melt crystallization

\section{Introduction}

Poly(vinylidene fluoride) (PVDF) is known for its polymorphism of five crystalline phases with different conformations, like all trans (TTTT) planar zigzag for $\beta$-phase, TGTG' for $\alpha$ - and $\delta$-phases and $\mathrm{T}_{3} \mathrm{GT}_{3} \mathrm{G}^{\prime}$ for $\gamma$ - and $\varepsilon$-phases $[1,2]$. If the PVDF chains pack in crystals to form parallel dipoles, the crystal possesses a net dipole moment as in polar form $\beta$-, $\gamma$ - and $\delta$-phases; whereas, in antiparallel chain dipoles, the net dipole moment vanishes as in non-polar $\alpha$ - and $\varepsilon$-phases [3]. $\alpha$ - and $\beta$-phases are most popular among the five. $\alpha$-phase is obtained directly from the melt [4-6] and $\beta$-phase is usually obtained from solution under $70^{\circ} \mathrm{C}$ [7] or by the mechanical stretching of $\alpha$-phase films to a certain percent elongation at a given temperature.
PVDF can be blended with hydrophilic or polar polymers, such as poly(methyl methacrylate) (PMMA) [8, 9], poly(vinylpyrrolidone) (PVP) [10], polyacrylonitrile (PAN) [11], poly(vinyl acetate) (PVAc) [12], poly(3-hydroxybutyrate) (PHB) [13] to improve its hydrophilicity. From an exclusively thermodynamic point of view, the blends may be classified as miscible, partially miscible, and immiscible systems [14]. Among these polymers, PMMA (at- or syn-) was miscible with PVDF; PAN was partially miscible with PVDF. Besides these homopolymers, more and more attention has been concentrated onto copolymers, like PMMA-b-PEO, or others. We also used poly(styrene-co-acrylonitrile) (SAN) copolymer to melt blend with PVDF in our previous works. The

*Corresponding author, e-mail: zhangjun@ njut.edu.cn (C) BME-PT 
miscibility of PVDF/SAN (acrylonitrile content $=$ $26 \mathrm{wt} \%$ ) blends, lamellar thickness, the crystallinity and the hydrophilicity of PVDF depended on the content of SAN, and only $\alpha$-phase PVDF was obtained from the melt crystallization [15].

In this work, the solution casting method was used to prepare the PVDF/SAN blend with an acrylonitrile content of $33 \mathrm{wt} \%$ in solvent N,N-dimethylformamide (DMF). The effects of adding SAN on the crystallization behavior and crystal structure of PVDF was studied. Differential scanning calorimetry (DSC) was used to study the crystallization behaviors of PVDF in the blend. The crystal structures and forms were determined by wide angle $\mathrm{X}$ ray diffraction (WAXD) and Fourier transform infrared spectroscopy (FTIR).

\section{Experimental}

\subsection{Materials}

PVDF $\left(\bar{M}_{w}=371000, \bar{M}_{w} / \bar{M}_{n}=2.5\right)$ was supplied by Elf Atochem of North America Inc. (USA). SAN (acrylonitrile content is $33 \mathrm{wt} \%$ ) was purchased from Zhenjiang Guoheng Chemical Co., Ltd (China). DMF was obtained from Sinopharm Chemical Reagent Co., Ltd (China). All the chemicals are used as received.

\subsection{Film preparation}

Homogeneous solutions were obtained by dissolving the blends with different PVDF content (100, $90,80,70,50,20$ and $0 \mathrm{wt} \%$ ) in DMF at $50^{\circ} \mathrm{C}$. The initial polymer concentration of the solution was $5 \mathrm{wt} \%$. After evaporation of the solvent for $24 \mathrm{~h}$ at $50^{\circ} \mathrm{C}$ in a vacuum oven, the films were peeled from the glass substrates. The melt blending of PVDF/ SAN was prepared at $180^{\circ} \mathrm{C}$ using a torque rheogoniometer (Shanghai Kechuang Machinery XSS300 , China) with the rotor speed of $60 \mathrm{r} / \mathrm{min}$ for 5 min and with different PVDF content (100, 90, $80,70,50,20$ and $0 \mathrm{wt} \%$ ).

\subsection{Characterization techniques}

FTIR spectroscopy was performed using spectrometer (Vector-22, Bruker, Germany) with a nominal resolution of $4 \mathrm{~cm}^{-1}$ at 32 scans. The content of $\beta$-phase was characterized by the absorbance ratio $A_{\beta}$ of the FTIR absorption peaks at $839 \mathrm{~cm}^{-1}$ and peaks at $2980 \mathrm{~cm}^{-1}$ as Equation (1):

$$
A_{\beta}=\frac{A_{839}}{A_{2980}}
$$

where $A_{839}$ represented the FTIR absorbance peak height at $839 \mathrm{~cm}^{-1}$, characteristic of $\beta$-phase. The absorbance peak height at $2980 \mathrm{~cm}^{-1}$ (independent on the crystalline phase of PVDF [16] and SAN contents) was regarded as constant.

DSC was conducted using a TA Instruments Q-200 (USA) under a dry nitrogen atmosphere. The sample $(10 \mathrm{mg})$ was first heated from room-temperature to $200^{\circ} \mathrm{C}$ at a rate of $10^{\circ} \mathrm{C} / \mathrm{min}$ and kept at this temperature for $3 \mathrm{~min}$ to eliminate thermal history, followed by the scan to $0^{\circ} \mathrm{C}$ at a cooling rate of $5^{\circ} \mathrm{C} / \mathrm{min}$, finally a heating rate of $10^{\circ} \mathrm{C} / \mathrm{min}$ to $200^{\circ} \mathrm{C}$. The degree of crystallinity $X_{c}$ was evaluated according to Equation (2) [17]:

$$
X_{c}=\frac{\Delta H_{f} / \phi}{\Delta H_{f}^{*}} \cdot 100 \%
$$

where $\Delta H_{f}$ was the endothermic heat during the melting process and $\Delta H_{f}^{*}$ was the heat fusion of a perfect crystal, taken as $104.5 \mathrm{~J} / \mathrm{g}$ [18] for PVDF. $\phi$ was the weight fraction of PVDF in the blend.

WAXD was done in a Shimadzu XRD-6000 diffractometer (Japan) with the current of $30 \mathrm{~mA}$, the accelerating voltage of $40 \mathrm{kV}$, and the scanning velocity of $4^{\circ} / \mathrm{min}$ with $0.04^{\circ}$ steps over the $2 \theta$ ranged from $5 \sim 50^{\circ}$ using $\mathrm{Cu}-\mathrm{K}_{\alpha}$ radiation. For further analysis, the interplanar spacing $d$ and the lamellar thickness $L$ were calculated according to Equations (3) and (4) [19]:

$$
\begin{aligned}
& d=\frac{\lambda}{2 \sin \theta} \\
& L=\frac{k \lambda}{\varphi \cos \theta}
\end{aligned}
$$

where $\lambda$ is the wavelength of the $\mathrm{X}$-ray, taken as $0.1542 \mathrm{~nm} ; \theta$ is the half of the scanning angle; $k$ is Scherrer constant, taken as 1 ; and $\varphi$ is the full width at half maximum (FWHM) of the diffraction peak. 


\section{Results and discussion}

\subsection{FTIR}

FTIR spectra of two major phases ( $\alpha$ - and $\beta$-phases) of PVDF has been under intensive investigation recently [20-22]. Vibrational bands at around $530 \mathrm{~cm}^{-1}\left(\mathrm{CF}_{2}\right.$ bending), 615 and $765 \mathrm{~cm}^{-1}\left(\mathrm{CF}_{2}\right.$ bending and skeletal bending) and $795 \mathrm{~cm}^{-1}\left(\mathrm{CH}_{2}\right.$ rocking) refer to $\alpha$-phase. Vibrational bands at around $510 \mathrm{~cm}^{-1}\left(\mathrm{CF}_{2}\right.$ bending $)$ and $839 \mathrm{~cm}^{-1}\left(\mathrm{CH}_{2}\right.$ rocking) correspond to $\beta$-phase [16, 23].

Figure 1 shows the FTIR spectra of PVDF blends with different weight fractions of SAN (PVDF/ SAN: a) $100 / 0$; b) $90 / 10$; c) $80 / 20$; d) $70 / 30$; e) $50 / 50$; f) $20 / 80$; g) $0 / 100$ ) crystallized in DMF at $50^{\circ} \mathrm{C}$. For PVDF, 3020 and $2980 \mathrm{~cm}^{-1}$ were attributed to the symmetrical and asymmetrical stretching vibration of $\mathrm{CH}_{2}[16,24]$. For SAN, two peaks at 2930 and $2850 \mathrm{~cm}^{-1}$ corresponded to the $\mathrm{CH}_{2}$ vibration. The vibration of $\mathrm{C} \equiv \mathrm{N}$ band of $\mathrm{SAN}$ appeared at $2237 \mathrm{~cm}^{-1}$ [25]. The existence of styrene segment in the blends was represented by

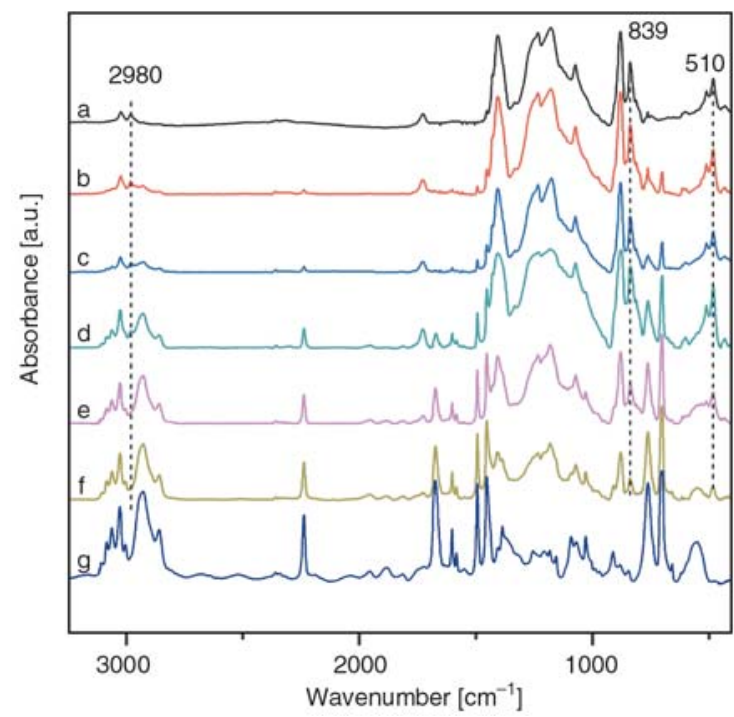

Figure 1. FTIR spectra of PVDF, SAN, and their blends with various mass ratios: a) 100/0; b) $90 / 10$; c) $80 / 20$; d) $70 / 30$; e) $50 / 50$; f) $20 / 80$; g) $0 / 100$ the aromatic $\mathrm{C}-\mathrm{H}$ stretching at around 3010$3100 \mathrm{~cm}^{-1}$, the out-of-plane hydrogen vibration at the $759 \mathrm{~cm}^{-1}$, and the benzene ring $\mathrm{C}=\mathrm{C}$ out-ofplane bending at $699 \mathrm{~cm}^{-1}[25,26]$. For PVDF as prepared, there also existed weak absorption peaks at 530, 613 and $763 \mathrm{~cm}^{-1}$ corresponded to $\alpha$-phase. However, the absorption peaks at 530 and $763 \mathrm{~cm}^{-1}$ were overlapped with other absorption peaks from SAN when SAN content was increased over $20 \mathrm{wt} \%$. Thus, the detailed crystal forms seemed unobservable from the FTIR spectra when SAN content increased.

In Figure 2, we employed an index $A_{\beta}$ to detect the crystal forms of PVDF with solution-blended SAN. According to Figure 2, it was obvious that the content of $\beta$-phase of PVDF has a tendency to decrease with the increasing content of SAN. However, there also was a possibility: the whole degree of crystallinity of PVDF decreased with the increasing content of SAN, so that the decrease of $\beta$-phase happened. Considering this hypothesis, we divided $A_{\beta}$ by $X_{c}$ from Table 1 (later in chapter 3.2). It was also supporting the conclusion that blended SAN could decrease the content of $\beta$-phase of PVDF.

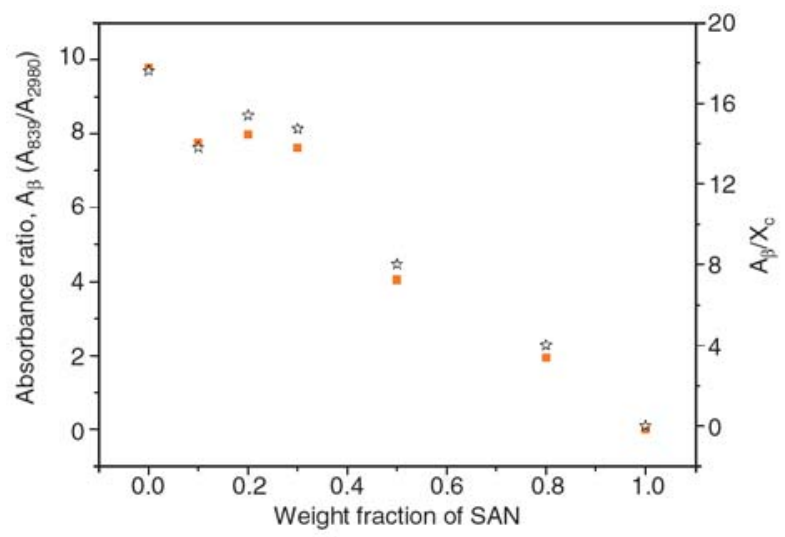

Figure 2. $\beta$ phase content ( $\square$ : $A_{\beta}$ from Figure 1 and $\star: A_{\beta} / X_{c}$ from Table 1$)$ vs. SAN weight fraction of PVDF/SAN blends

Table 1. DSC data of melting traces of PVDF/SAN blends under solution molding with various mass ratios

\begin{tabular}{|c|c|c|c|c|c|c|c|}
\hline $\begin{array}{c}\text { Sample } \\
\text { PVDF/SAN }\end{array}$ & $\begin{array}{c}\mathbf{T}_{\mathbf{g}, \mathbf{S A N}} \\
{\left[{ }^{\mathbf{C}} \mathbf{C}\right]}\end{array}$ & $\begin{array}{c}\mathbf{T}_{\mathbf{m}}^{\mathbf{n}} \\
{\left[{ }^{\circ} \mathbf{C}\right]}\end{array}$ & $\begin{array}{c}\mathbf{T}_{\mathbf{m}}^{\mathbf{p}} \\
{\left[{ }^{\circ} \mathbf{C}\right]}\end{array}$ & $\begin{array}{c}\mathbf{T}_{\mathbf{m}}^{\mathbf{f}} \\
{\left[{ }^{\circ} \mathbf{C}\right]}\end{array}$ & $\begin{array}{c}\Delta \mathbf{T}_{\mathbf{m}} \\
{\left[{ }^{\circ} \mathbf{C}\right]}\end{array}$ & $\begin{array}{c}\Delta \mathbf{H}_{\mathbf{m}} \\
{[\mathbf{J} / \mathbf{g}]}\end{array}$ & $\begin{array}{c}\mathbf{X}_{\mathbf{c}} \\
{[\mathbf{\%}]}\end{array}$ \\
\hline $100 / 0$ & - & 147.0 & 169.6 & 176.3 & 29.3 & 58.01 & 55.51 \\
\hline $90 / 10$ & - & 146.6 & 169.1 & 176.5 & 29.9 & 52.76 & 56.10 \\
\hline $80 / 20$ & - & 146.2 & 168.9 & 175.6 & 29.4 & 43.28 & 51.77 \\
\hline $70 / 30$ & - & 145.4 & 167.8 & 174.3 & 28.9 & 37.81 & 51.69 \\
\hline $50 / 50$ & 84.2 & 143.6 & 166.1 & 173.3 & 29.7 & 26.36 & 50.45 \\
\hline $20 / 80$ & 81.6 & 143.3 & 163.0 & 169.8 & 26.5 & 10.09 & 48.28 \\
\hline $0 / 100$ & 86.6 & - & - & - & - & - & - \\
\hline
\end{tabular}

$T_{m}^{o n}$ : onset melting temperature of PVDF; $T_{m}^{p}$ : peak melting temperature of PVDF; $T_{m}^{f}$ : final melting temperature of PVDF; $\Delta T_{m}=T_{m}^{f}-T_{m}^{o n} ; \Delta H_{m}$ : melting enthalpy of blend; $X_{c}$ : crystallinity of PVDF 


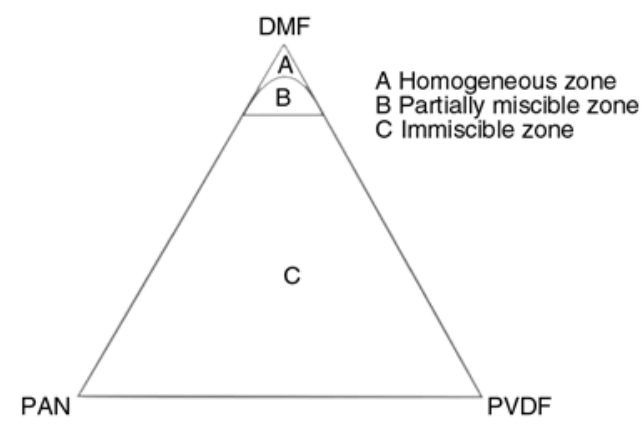

Figure 3. A schematic presentation of PVDF/PAN/DMF phase diagram [29]

In solution crystallization, dipoles of the mixtures had important effects on the crystallization of PVDF in the solution. The stronger dipolar interactions between PVDF and DMF might induce the trans conformation packing of $\mathrm{CH}_{2}-\mathrm{CF}_{2}$ dipoles of $\beta$-phase [27]. Mixtures with lower dipole moment resulted in the nonpolar $\alpha$-phase [28]. Figure 3 is a schematic presentation of PVDF/PAN/DMF phase diagram which demonstrates that PAN and PVDF belong to partially miscible systems by adding small amount of PVDF or PAN into the solution [29]. SAN is a copolymer of styrene and acrylonitrile comonomer. The nonpolar styrene segment in SAN copolymer further reduces the homogenous and partially miscible zones. However, this nonpolar styrene also reduces the number of dipoles in the mixtures which favors the formation the nonpolar $\alpha$-phase [28]. As used SAN has 33 wt $\%$ AN, in the sample of $10 \mathrm{wt} \%$ SAN blended PVDF mixture, there is $3.3 \mathrm{wt} \%$ AN which might have good miscibility with PVDF. So that nonpolar styrene around acrylonitrile comonomer has more effect on the crystallization of PVDF. In Figure 2, the observation that $A_{\beta}$ has an abrupt decrease for $10 \mathrm{wt} \% \mathrm{SAN}$ blended PVDF mixture could be interpreted by the above analysis.

\subsection{DSC}

Figure 4 presents DSC melting traces of PVDF/ SAN blends obtained under solution molding with various mass ratios (a) $100 / 0$; b) $90 / 10$; c) $80 / 20$; d) $70 / 30$; e) $50 / 50$; f) 20/80; g) 0/100). The detailed data derived from Figure 4 were listed in Table 1.

As shown in Figure 4, when SAN content exceeded $50 \mathrm{wt} \%$, glass transition temperature of SAN $\left(T_{g}\right.$,SAN $)$ became discernable. The glass transition

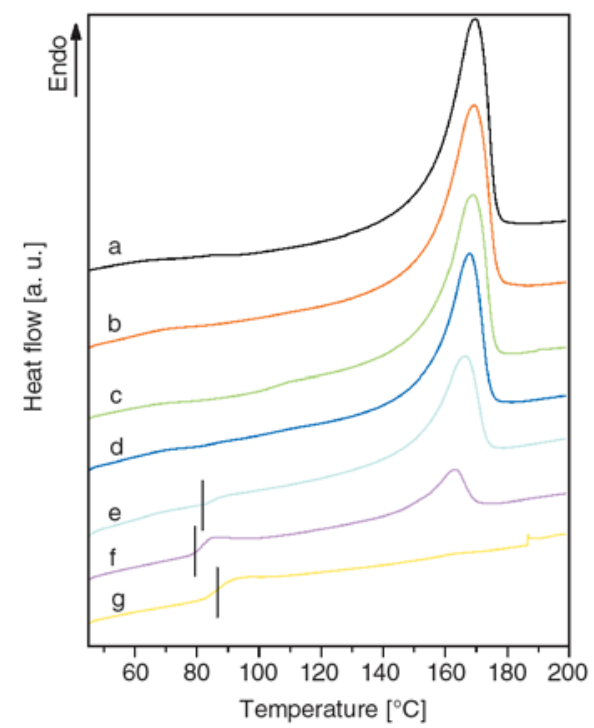

Figure 4. DSC melting traces of PVDF/SAN blends under solution molding with various mass ratios:

a) $100 / 0$; b) $90 / 10$; c) $80 / 20$; d) $70 / 30$; e) $50 / 50$; f) $20 / 80 ;$ g) $0 / 100$

temperature of PVDF was $-39^{\circ} \mathrm{C}$ [30]. The glass transition temperature of SAN was $86.6^{\circ} \mathrm{C}$ in Table 1. For the sample of PVDF/SAN $=20 / 80$, the small content of PVDF also made the system partially miscible according to Figure 3 , so that the $T_{g, \text { SAN }}$ decreased to $81.6^{\circ} \mathrm{C}$; but for sample of $\mathrm{PVDF} / \mathrm{SAN}=50 / 50$, miscibility decreased so that the $T_{g, \text { SAN }}$ had a relative increase to be $84.2^{\circ} \mathrm{C} \mathrm{com-}$ pared with the sample of PVDF/SAN $=20 / 80$.

For pure PVDF crystallized from $5 \mathrm{wt} \% \mathrm{DMF}$ solution, the single melting peak at about $169.6^{\circ} \mathrm{C}$ can be attributed to the melting of $\beta$-phase with small amounts of $\alpha$-phase [7, 23, 31, 32]. As SAN content increased in the blends, the melting enthalpy and melting point decreased. In Table 1, the influence of SAN component on PVDF crystallization was decreasing the onset of melting temperature $\left(T_{m}^{o n}\right)$, the final melting temperature $\left(T_{m}^{f}\right)$ and the peak melting temperature $\left(T_{m}^{p}\right)$. Small amount of SAN of $10 \mathrm{wt} \%$ did not show any effect on the crystallinity of PVDF. When SAN exceeded $20 \mathrm{wt} \%$, it decreased $X_{c}$ by about $4-5 \%$. The crystallinity of PVDF had the tendency to decrease with increase of SAN content in the blends. However, the lower acrylonitrile content based PVDF/SAN (D-178, acrylonitrile content $=26 \mathrm{wt} \%$ ) is a partially miscible system [15]. In this work, the higher acrylonitrile units in SAN (D-168, acrylonitrile content $=33 \mathrm{wt} \%$ ) result in worse miscibility. In addition, the low concentration (5 wt \%) solution, 
which results in the good mobility of the PVDF molecular chains, also favors the crystallization of PVDF. PVDF can crystallize independently in a wide range of concentration. Therefore, the difference in the crystallinity of PVDF in the blends cannot be so remarkable. Likewise, the $\Delta T_{m}=T_{m}^{f}-T_{m}^{o n}$ also had no distinct changes, which suggested that blending SAN did not decrease the crystal homogeneity of PVDF, except the sample with a SAN content of $80 \mathrm{wt} \%$.

For comparability, DSC melting traces of PVDF/ SAN blends after eliminating thermal history with various mass ratios (PVDF/SAN: a) 100/0; b) $90 / 10$; c) $80 / 20$; d) $70 / 30$; e) $50 / 50$; f) $20 / 80$; g) 0/100) are shown in Figure 5. The detailed data derived from Figure 5 were listed in Table 2. These PVDF/SAN blends were prepared by melt molding as in our previous work [15].

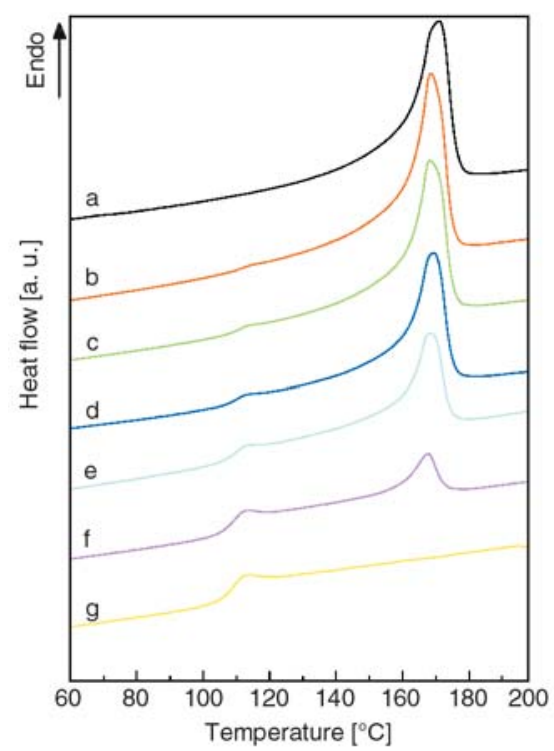

Figure 5. DSC melting traces of PVDF/SAN blends after eliminating thermal history with various mass ratios: a) $100 / 0$; b) $90 / 10$; c) $80 / 20$; d) $70 / 30$; e) $50 / 50$; f) $20 / 80$; g) $0 / 100$.
For pure SAN by melt molding, $T_{g, \mathrm{SAN}}$ was $109.3^{\circ} \mathrm{C}$. For sample of PVDF/SAN $=80 / 20$ by melt molding, $T_{g, \mathrm{SAN}}$ was $111.2^{\circ} \mathrm{C}$. As PVDF content increased, $T_{g, \text { SAN }}$ had an obvious increase. This situation is contrast to that obtained by solution casting. A reasonable explanation should consider the incorporation of SAN into inter spacing of PVDF lamellae, which was similar to the PVDF/ PMMA system [9]. When PVDF/SAN blends were prepared by casting from $5 \mathrm{wt} \%$ DMF solution, viscosity was low and PVDF molecular chains had mobility to retreat from the SAN's embrace; however, when PVDF/SAN blends were prepared by melt molding, viscosity was high and PVDF molecular chains had less mobility to crystallize despite of the exit of SAN. So with decreasing of SAN content, the ratio of incorporated PVDF increased and the $T_{g, \text { SAN }}$ increased. Besides, $T_{g, \text { SAN }}$ by solution casting was much lower than $T_{g, \text { SAN }}$ by melt molding, which might be attributed to the entanglement which has been intensively studied $[33,34]$. In Table 2, the addition of SAN did not show obvious effect on the melting temperatures of PVDF until SAN exceeded $20 \mathrm{wt} \%$, which resulted in similar $\Delta T_{m}=T_{m}^{f}-T_{m}^{o n}$. However, the crystallinity $X_{c}$ of PVDF crystallized from the melt increases from 41.58 to $47.41 \%$ by a little incorporation of SAN $(\leq 10 \mathrm{wt} \%)$. And at higher addition, it is reduced. The change of $X_{c}$ in Table 2 could also be explained based on the hypothesis of incorporation of SAN into inter spacing of PVDF lamellae. The partially miscible SAN had mobility when PVDF began to crystallize before $111.2^{\circ} \mathrm{C}$. In other words, SAN could be the diluent when PVDF began to crystallize, especially SAN was small amount of the blends because of the above-mentioned reason. Therefore, the crystallinity of PVDF in blends in Table 2 were mostly higher that that of the pure

Table 2. DSC melting results of PVDF/SAN blends after eliminating thermal history with different compositions

\begin{tabular}{|c|c|c|c|c|c|c|c|}
\hline $\begin{array}{c}\text { Sample } \\
\text { PVDF/SAN }\end{array}$ & $\begin{array}{c}\mathbf{T}_{\mathbf{g}, \mathbf{S A N}} \\
{\left[{ }^{\circ} \mathbf{C}\right]}\end{array}$ & $\begin{array}{c}\mathbf{T}_{\mathbf{m}}^{\mathbf{0}} \\
{\left[{ }^{\circ} \mathbf{C}\right]}\end{array}$ & $\begin{array}{c}\mathbf{T}_{\mathbf{m}}^{\mathbf{p}} \\
{\left[{ }^{\circ} \mathbf{C}\right]}\end{array}$ & $\begin{array}{c}\mathbf{T}_{\mathbf{m}}^{\mathbf{f}} \\
{\left[{ }^{\circ} \mathbf{C}\right]}\end{array}$ & $\begin{array}{c}\Delta \mathbf{T}_{\mathbf{m}} \\
{\left[{ }^{\circ} \mathbf{C}\right]}\end{array}$ & $\begin{array}{c}\Delta \mathbf{H}_{\mathbf{m}} \\
{[\mathbf{J} / \mathbf{g}]}\end{array}$ & $\begin{array}{c}\mathbf{X}_{\mathbf{c}} \\
{[\mathbf{\%}]}\end{array}$ \\
\hline $100 / 0$ & - & 160.7 & 171.0 & 176.4 & 15.7 & 43.45 & 41.58 \\
\hline $90 / 10$ & - & 161.2 & 168.4 & 175.1 & 13.9 & 44.59 & 47.41 \\
\hline $80 / 20$ & 111.2 & 160.9 & 168.1 & 175.2 & 14.3 & 38.85 & 46.47 \\
\hline $70 / 30$ & 110.6 & 160.4 & 169.1 & 175.0 & 14.6 & 33.57 & 45.89 \\
\hline $50 / 50$ & 110.0 & 160.3 & 168.1 & 174.3 & 14.0 & 22.22 & 42.53 \\
\hline $20 / 80$ & 109.6 & 158.4 & 167.6 & 172.8 & 14.4 & 8.47 & 40.52 \\
\hline $0 / 100$ & 109.3 & - & - & - & - & - & - \\
\hline
\end{tabular}

$T_{m}^{o n}$ : onset melting temperature of PVDF; $T_{m}^{p}$ : peak melting temperature of PVDF; $T_{m}^{f}$ : final melting temperature of PVDF; $\Delta T_{m}=T_{m}^{f}-T_{m}^{o n} ; \Delta H_{m}$ : melting enthalpy of blend; $X_{c}$ : crystallinity of PVDF 
PVDF obtained by melt molding, except the sample of $\mathrm{PVDF} / \mathrm{SAN}=20 / 80$, which was probably because too much SAN restricted the mobility of PVDF chains.

\subsection{WAXD}

The wide angle X-ray diffraction of PVDF/SAN blends are shown in Figure 6. The diffraction peak at $2 \theta$ of about $20.5^{\circ}$ is corresponding to the (110) and (200) combined reflections of the $\beta$-form [23, 35 ] and the small peak at about $40^{\circ}$ is assigned to the combined reflections of (201) and (111) planes of the $\beta$-phase [36]. It is demonstrated that all the solution cast samples, regardless of the various SAN weight fractions in the blend, present predominantly the $\beta$-phase. The two peaks here both decreased their intensity when the SAN was added, especially for the peak at $2 \theta$ of about $40^{\circ}$, when the content of SAN was larger than $20 \mathrm{wt} \%$, it even

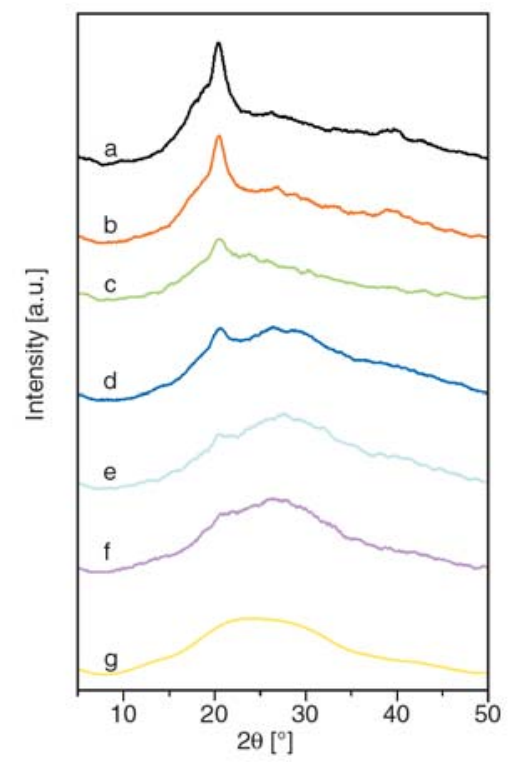

Figure 6. X-ray diffractograms of PVDF/SAN blends under solution molding with different mass ratios: a) $100 / 0$; b) $90 / 10$; c) $80 / 20$; d) 70/30; e) $50 / 50$; f) $20 / 80$; g) $0 / 100$. disappeared. WAXD results further confirm that the addition of SAN hinders the crystallization of PVDF. According to the FTIR results, solution crystallized samples with a little incorporation of SAN ( $\leq 10 \mathrm{wt} \%)$ presents $\beta$-phase with a small amount of $\alpha$-phase, but it is so little that it can just be detected by FTIR measurement. WAXD result demonstrates that $\beta$-phase of PVDF is present predominantly in solution crystallized samples.

Detailed data of WAXD are listed in Table 3. As shown in Table 3, there was no distinct change for $d$ value between the different samples, i.e., the lattices parameter of the $\beta$-phase was not affected by SAN. All the observed $L$ values were higher than that of the neat PVDF. The results were similar to those obtained from PVDF/PMMA blend [9]. In the miscible binary blend system including crystalline and non-crystalline component, the noncrystalline component can be sandwiched in the regions between lamella; that is the lamellar thickness $L$ increases as the non-crystalline polymer composition increases $[9,37]$.

\section{Conclusions}

In this study, FTIR, DSC and WAXD were used to characterize the effect of solution-blended SAN with acrylonitrile content $33 \mathrm{wt} \%$ on the crystallization of PVDF. By FTIR, typical 510 and $839 \mathrm{~cm}^{-1}$ was corresponded to the $\beta$-phase of PVDF in the PVDF/SAN blends. There also existed weak absorption peaks at 530, 613 and $763 \mathrm{~cm}^{-1}$ corresponding to $\alpha$-phase. Blended SAN could decrease the content of $\beta$-phase of PVDF from the index $A_{\beta} / X_{c}$. Nonpolar styrene reduced the dipoles of the mixtures which favored the formation the nonpolar $\alpha$-phase. Through the DSC analysis, the smaller content of PVDF made the system more miscible so that the $T_{g, \mathrm{SAN}}$ of pure SAN decreased

Table 3. WAXD data of PVDF/SAN blends under melt molding with various mass ratios

\begin{tabular}{|c|c|c|c|c|c|c|}
\hline \multirow{2}{*}{$\begin{array}{c}\text { Sample } \\
\text { PVDF/SAN }\end{array}$} & \multicolumn{3}{|c|}{ hkl $(110,200)$} & \multicolumn{3}{|c|}{ hkl $(201,111)$} \\
\hline & $2 \theta\left[{ }^{\circ}\right]$ & $d[\AA]$ & $\mathbf{L}[\AA]$ & $2 \theta\left[^{\circ}\right]$ & $d[\AA]$ & $\mathbf{L}[\AA]$ \\
\hline $100 / 0$ & 20.40 & 4.35 & 67.7 & 39.72 & 2.27 & 391.4 \\
\hline $90 / 10$ & 20.36 & 4.36 & 81.3 & 39.87 & 2.26 & 306.4 \\
\hline $80 / 20$ & 20.36 & 4.36 & 74.8 & 39.80 & 2.26 & - \\
\hline $70 / 30$ & 20.44 & 4.34 & - & 39.57 & 2.27 & - \\
\hline $50 / 50$ & - & - & - & - & - & - \\
\hline $20 / 80$ & - & - & - & - & - & - \\
\hline $0 / 100$ & - & - & - & - & - & - \\
\hline
\end{tabular}

-: not observed; $\theta$ : bragg angle; $d$ : the interplanar distance; $L$ : the thickness of the lamellar crystal $\left(1 \AA=10^{-10} \mathrm{~m}\right)$ 
from 86.6 to $81.6^{\circ} \mathrm{C}$ of sample $\mathrm{PVDF} / \mathrm{SAN}=$ 20/80; further adding PVDF to 50/50, the $T_{g, S A N}$ had a relative increase to be $84.2^{\circ} \mathrm{C}$. However, for SAN obtained by melt molding, $T_{g, \text { SAN }}$ increased with the increase of PVDF content, which might be due to the incorporation of SAN into inter spacing of PVDF lamellae because PVDF molecular chains had not enough mobility to retreat from the SAN's embrace and crystallize despite of the exit of SAN. According to the WAXD analysis, all the solution casting samples, regardless of the various SAN weight fractions in the blend, present predominantly the $\beta$-phase.

\section{Acknowledgements}

This work is supported by the National Basic Research Program of China under contract No. 2009CB623404.

\section{References}

[1] Broadhurst M. G., Davis G. T., McKinney J. E.: Piezoelectricity and pyroelectricity in polyvinylidene fluoride - A model. Journal of Applied Physics, 49, 4992-4997 (1978).

DOI: $10.1063 / 1.324445$

[2] Lovinger A. J.: Annealing of poly(vinylidene fluoride) and formation of a fifth phase. Macromolecules, 15, 40-44 (1982). DOI: $\underline{10.1021 / \mathrm{ma} 00229 \mathrm{a} 008}$

[3] Salimi A., Yousefi A. A.: Analysis method: FTIR studies of $\beta$-phase crystal formation in stretched PVDF films. Polymer Testing, 22, 699-704 (2003). DOI: $10.1016 / \mathrm{S} 0142-9418(03) 00003-5$

[4] Jungnickel B. J.: Poly (vinylidene fluoride). in 'Polymeric materials handbook' (ed.: Salamone J.C.) CRC Press Inc, NewYork, 7115-7122 (1999).

[5] El Mohajir B-E., Heymans N.: Changes in structural and mechanical behaviour of PVDF with processing and thermomechanical treatments. 1. Change in structure. Polymer, 42, 5661-5667 (2001). DOI: 10.1016/S0032-3861(01)00064-7

[6] Sajkiewicz P., Wasiak A., Goclowski Z.: Phase transitions during stretching of poly(vinylidene fluoride). European Polymer Journal, 35, 423-429 (1999). DOI: 10.1016/S0014-3057(98)00136-0

[7] Gregorio J. R., Cestari M.: Effect of crystallization temperature on the crystalline phase content and morphology of poly(vinylidene fluoride). Journal of Polymer Science Part B: Polymer Physics, 32, 859-870 (1994).

DOI: $\underline{10.1002 / \text { polb.1994.090320509 }}$
[8] Huang C., Zhang L.: Miscibility of poly(vinylidene fluoride) and atactic poly(methyl methacrylate). Journal of Applied Polymer Science, 92, 1-5 (2004). DOI: 10.1002/app.13564

[9] Ma W., Zhang J., Wang X., Wang S.: Effect of PMMA on crystallization behavior and hydrophilicity of poly(vinylidene fluoride)/poly(methyl methacrylate) blend prepared in semi-dilute solutions. Applied Surface Science, 253, 8377-8388 (2007).

DOI: 10.1016/j.apsusc.2007.04.001

[10] Chen N. P., Hong L.: Surface phase morphology and composition of the casting films of PVDF-PVP blend. Polymer, 43, 1429-1436 (2002). DOI: $10.1016 / \mathrm{S} 0032-3861(01) 00671-1$

[11] Liu T-Y., Lin W-C., Huang L-Y., Chen S-Y., Yang M-C.: Surface characteristics and hemocompatibility of PAN/PVDF blend membranes. Polymers for Advanced Technologies, 16, 413-419 (2005). DOI: $10.1002 /$ pat.592

[12] Chiu H-J.: Spherulitic morphology and crystallization kinetics of poly(vinylidene fluoride)/poly(vinyl acetate) blends. Journal of Polymer Research, 9, 169-174 (2002). DOI: $10.1023 / \mathrm{A}: 1021387524243$

[13] Liu J. P., Jungnickel B-J.: Crystallization and morphology of poly(vinylidene fluoride)/poly(3-hydroxybutyrate) blends. I. Spherulitic morphology and growth by polarized microscopy. Journal of Polymer Science Part B: Polymer Physics, 41, 873-882 (2003). DOI: $10.1002 /$ polb.10454

[14] Linares A., Acosta J. L.: Compatibility studies of partially compatible blends through glass transition temperature and melting point depression analysis. Journal of Applied Polymer Science, 67, 997-1004 (1998).

DOI: 10.1002/(SICI)1097-4628(19980207)67:6<997:: AID-APP5>3.0.CO;2-H

[15] Ma W., Zhang J., Chen S., Wang X.: Crystallization behavior and hydrophilicity of poly (vinylidene fluoride) (PVDF)/poly (styrene-co-acrylonitrile) (SAN) blends. Colloid and Polymer Science, 286, 1193-1202 (2008).

DOI: $10.1007 / \mathrm{s} 00396-008-1889-8$

[16] Bachmann M. A., Gordon W. L., Koenig J. L., Lando J. B.: An infrared study of phase-III poly(vinylidene fluoride). Journal of Applied Physics, 50, 6106-6112 (1979). DOI: $10.1063 / 1.325780$

[17] Gu M., Zhang J., Wang X., Ma W.: Crystallization behavior of PVDF in PVDF-DMP system via thermally induced phase separation. Journal of Applied Polymer Science, 102, 3714-3719 (2006). DOI: $10.1002 /$ app. 24531 
[18] Nakawa K., Ishida Y.: Annealing effects in poly(vinylidene fluoride) as revealed by specific volume measurements, differential scanning calorimetry, and electron microscopy. Journal of Polymer Science: Polymer Physics Edition, 11, 2153-2171 (1973). DOI: $\underline{10.1002 / \text { pol.1973.180111107 }}$

[19] Suryanarayana C., Grant N. M.: X-ray diffraction: A practical approach. Plenum Press, New York (1998).

[20] Gregorio R., Capitao R. C.: Effect of crystallization rate on the formation of the polymorphs of solution cast poly(vinylidene fluoride). Polymer, 49, 40094016 (2008).

DOI: 10.1016/j.polymer.2008.07.010

[21] Buonomenna M., Macchi P., Davoli M., Drioli E.: Poly(vinylidene fluoride) membranes by phase inversion: The role the casting and coagulation conditions play in their morphology, crystalline structure and properties. European Polymer Journal, 43, 1557-1572 (2007).

DOI: 10.1016/j.eurpolymj.2006.12.033

[22] Abdelrazek E. M., Elashmawi I. S., Soliman M. A., Aly A.: Physical properties of $\mathrm{MnCl}_{2}$ fillers incorporated into a PVDF/PVC blend and their complexes. Journal of Vinyl and Additive Technology, 15, 171177 (2009). DOI: $10.1002 / \mathrm{vnl} .20188$

[23] Gregorio R.: Determination of the $\alpha, \beta$, and $\gamma$ crystalline phases of poly(vinylidene fluoride) films prepared at different conditions. Journal of Applied Polymer Science, 100, 3272-3279 (2006).

DOI: 10.1002/app.23137

[24] Narula G. K., Rashmi, Pillai P. K. C.: Investigations of solution-mixed PVDF/PMMA polyblends by thermal, structural, and dielectric techniques. Journal of Macromolecular Science Part B: Physics, 28, 25-49 (1989). DOI: $10.1080 / 00222348908212326$

[25] Choi Y. S., Xu M., Chung I. J.: Synthesis of exfoliated poly(styrene-co-acrylonitrile) copolymer/silicate nanocomposite by emulsion polymerization; Monomer composition effect on morphology. Polymer, 44, 6989-6994 (2003).

DOI: 10.1016/j.polymer.2003.08.020

[26] Sun Y-P., Lawson G. E., Bunker C. E., Johnson R. A., Ma B., Farmer C., Riggs J. E., Kitaygorodskiy A.: Preparation and characterization of fullerene-styrene copolymers. Macromolecules, 29, 8441-8448 (1996). DOI: $10.1021 / \mathrm{ma960579e}$

[27] He X., Yao K.: Crystallization mechanism and piezoelectric properties of solution-derived ferroelectric poly(vinylidene fluoride) thin films. Applied Physics Letters, 89, 112909/1-112909/3 (2006). DOI: $\underline{10.1063 / 1.2352799}$
[28] Benz M., Euler W. B., Gregory O. J.: The role of solution phase water on the deposition of thin films of poly(vinylidene fluoride). Macromolecules, 35, 2682 2688 (2002).

DOI: $\underline{10.1021 / \mathrm{ma} 011744 \mathrm{f}}$

[29] Olabisi O., Robeson L. M., Shaw M. T.: Polymerpolymer miscibility. Academic Press, New York, (1979).

[30] Seiler D. A.: PVDF in the chemical process industry. in 'Modern fluoropolymers' (ed.: Scheirs J.) Wiley, Chichester, 487-505 (1997).

[31] Campos J. S. C., Riberio A. A., Cardoso C. X.: Preparation and characterization of $\mathrm{PVDF} / \mathrm{CaCO}_{3}$ composites. Material Science and Engineering: B, 136, 123 128 (2007). DOI: $10.1016 /$ j.mseb.2006.09.017

[32] Ma W., Zhang J., Chen S., Wang X.: Crystalline phase formation of poly(vinylidene fluoride) from tetrahydrofuran/N,N-dimethylformamide mixed solutions. Journal of Macromolecular Science Part B: Physics, 47, 434-449 (2008). DOI: $10.1080 / 00222340801954811$

[33] Huang D. H., Yang Y. M., Zhuang G. Q., Li B. Y.: Influence of entanglements on the glass transition and structural relaxation behaviors of macromolecules. 1 . Polycarbonate. Macromolecules, 32, 6675-6678 (1999). DOI: $10.1021 / \mathrm{ma} 990581 \mathrm{~g}$

[34] Huang D. H., Yang Y. M., Zhuang G. Q., Li B. Y.: Influence of intermolecular entanglements on the glass transition and structural relaxation behaviors of macromolecules. 2. Polystyrene and phenolphthalein poly(ether sulfone). Macromolecules, 33, 461-464 (2000). DOI: $\underline{10.1021 / \mathrm{ma} 990786 \mathrm{p}}$

[35] Davis G. T., McKinney J. E., Broadhurst M. G., Roth S. C.: Electric-field-induced phase changes in poly(vinylidene fluoride). Journal of Applied Physics, 49, 4998-5002 (1978).

DOI: $10.1063 / 1.324446$

[36] Lovinger A. J., Davis D. D., Cais R. E., Kometani J. M.: The role of molecular defects on the structure and phase transitions of poly(vinylidene fluoride). Polymer, 28, 617-626 (1987). DOI: $10.1016 / 0032-3861(87) 90478-2$

[37] Martuscelli E., Canetti M., Vicini L., Seves A.: First results of small and wide angle X-ray scattering of poly(ethylene oxide)/poly(methyl methacrylate) binary blends. Polymer, 23, 331-334 (1982). DOI: $\underline{10.1016 / 0032-3861(82) 90328-7}$ 